Session Code ICES307 (Orion Multi-Purpose Crew Vehicle Environmental Control and Life Support System)

Authors: Amy Button, Jeffrey Sweterlitsch

\title{
Reduced Pressure Cabin Testing of the Orion Atmosphere
}

\section{Revitalization Technology}

\section{$\underline{\text { Abstract }}$}

An amine-based carbon dioxide $\left(\mathrm{CO}_{2}\right)$ and water vapor sorbent in pressure-swing regenerable beds has been developed by Hamilton Sundstrand and baselined for the Atmosphere Revitalization System for moderate duration missions of the Orion Multipurpose Crew Vehicle. In previous years at this conference, reports were presented on extensive Johnson Space Center testing of this technology in a sea-level pressure environment with simulated and actual human metabolic loads in both open and closed-loop configurations. In 2011, the technology was tested in an open cabin-loop configuration at ambient and two sub-ambient pressures to compare the performance of the system to the results of previous tests at ambient pressure. The testing used a human metabolic simulator with a different type of water vapor generation than previously used, which added some unique challenges in the data analysis. This paper summarizes the results of: baseline and some matrix testing at all three cabin pressures, increased vacuum regeneration line pressure with a high metabolic load, a set of tests studying $\mathrm{CO}_{2}$ and water vapor co-adsorption effects relative to model-predicted performance, and validation tests of flight program computer model predictions with specific operating conditions. 